\title{
Certas equivalências e aspirações em comum: Luiz Sérgio Person e a produção cinematográfica de São Paulo na década de 1960
}

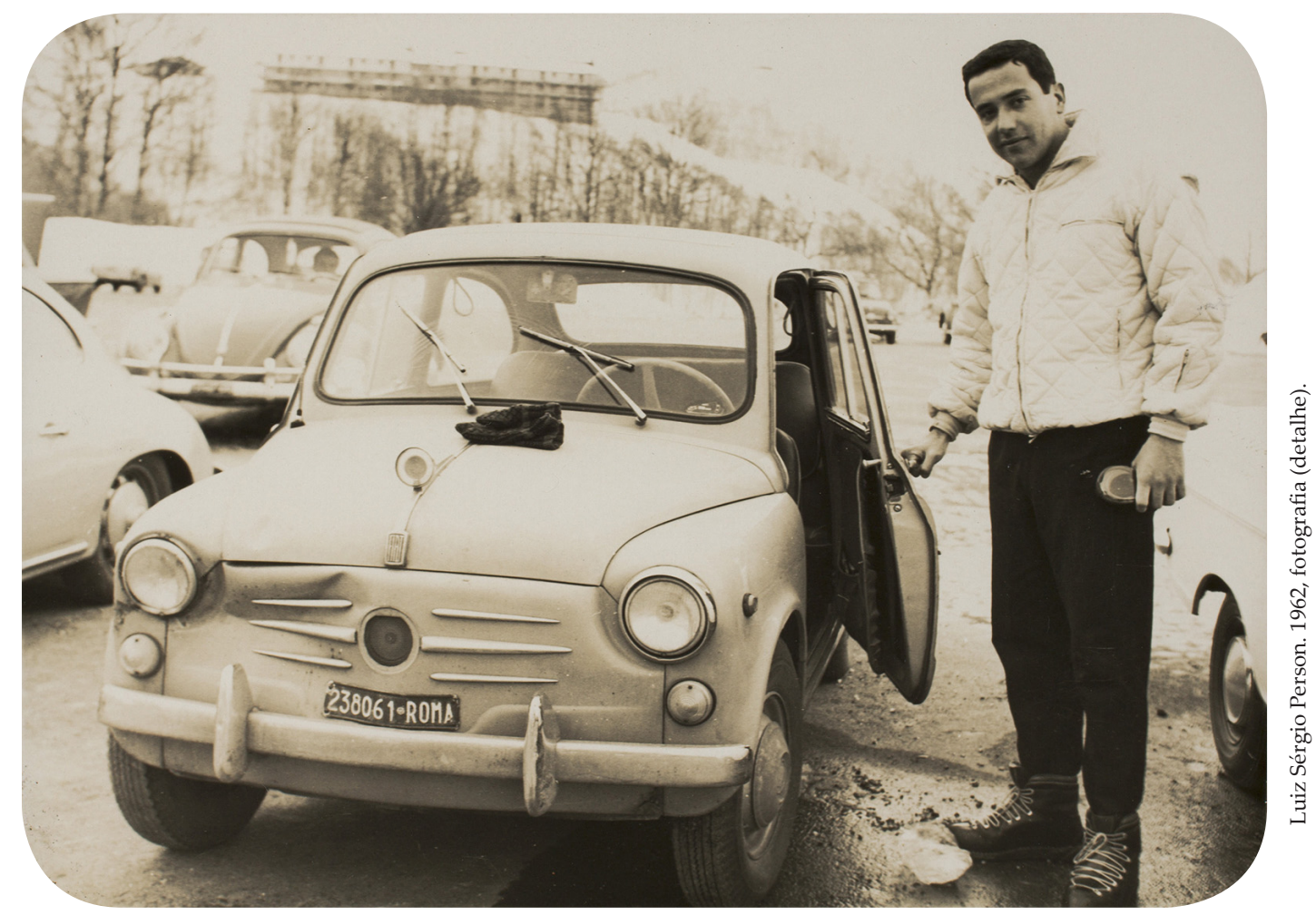

\section{Jaison Castro Silva}

Doutor em História Social pela Universidade Federal do Ceará (UFC). Professor do Instituto Federal do Piauí-campus Campo Maior (IFP) e do Programa de Pós-graduação em História da Universidade Federal do Piauí (UFPI). Coorganizador, entre outros livros, de História e arte: teatro, cinema, literatura. Teresina: Edufpi, 2016.

jaisoncastro@gmail.com 


\section{Certas equivalências e aspirações em comum: Luiz Sérgio Person e a produção cinematográfica de São Paulo na década de 1960*}

Equivalences and common aspirations: Luiz Sérgio Person and the São Paulo film production in the 1960's

\section{Jaison Castro Silva}

\section{RESUMO}

O texto analisa como o cineasta Luiz Sérgio Person se inseriu, ainda que de modo heterodoxo, no contexto cultural do cinema paulista. Durante muito tempo vinculado a outros movimentos cinematográficos, Person sempre manteve uma relação ambivalente com o cenário paulista, até que, a partir de 1966, o cineasta passou a representar um exemplo de cinema autoral diante de uma produção fílmica que, através do INC e da revista Filme Cultura, buscava construir um meio-caminho entre o cinema de autor e o cinema de indústria em sua proposta de constituição de um polo de produção cinematográfica. Apesar de sua inserção, Luiz Sérgio Person afirmou sua individualidade e seu não pertencimento a grupos em um contexto cultural em que isso poderia ocasionar um relativo isolamento. Sua trajetória singular mostra-se uma excepcional oportunidade para analisar as iniciativas individuais frente a um cenário em que as posições políticas geravam uma polarização aparentemente irremediável.

palavras-chave: Luiz Sergio Person; produção cinematográfica de São Paulo; década de 1960.

\section{ABSTRACT}

This article analyses how filmmaker Luís Sérgio Person fits, albeit in an unorthodox way, into the cultural experience of São Paulo cinema. For a long time, Person's trajectory has been seen as a part of other cinematographic movements. Person always had an ambivalent relationship with the cultural options defended by São Paulo film industry. Nevertheless, after 1966, he became an example of authorial cinema against a background of film production whose main focus was building a film production hub, which was supported INC and Filme Cultura magazine. This proposal had predicted the possibility of filmmaking that merge authorial ambitions and industrial requirements. Luís Sérgio defends his own individuality as uncommitted to any groups, but this led him to a relatively isolated path. His trajectory offers an outstanding opportunity to analyze individual positions in a political setting with an undeniable polarization between left and right.

KeYwords: Luís Sérgio Person; São Paulo cinema; authorial cinema.
${ }^{1}$ Uma escrita imagética (bildlich) é aquela em que as palavras se agregam para explodir em construtos de alto poder sensório. Em termos de pesquisa relacionada a cinema, essa abordagem teórica faz-se fundamental para permitir que a historicidade de manifestações singulares assome em suas contradições, hábeis para compor um nó temporal inelidível. DIDI-HUBERMAN, Georges. O que vemos, o que nos olha. 2. ed. São Paulo: Editora 34, 1998, p. 181 e ss.; BENJAMIN, Walter. Magia e técnica, arte e política. 7. ed. São Paulo: Brasiliense, 1994. 
mente as experiências fílmicas com temática urbana que se seguiriam.

A imagem construída pelo impulso autoral personiano abriu no campo do cinema brasileiro, naquele momento em vias de consolidação, um lugar privatizado, cavando-o, por assim dizer, com suas próprias mãos. ${ }^{1}$ As iniciativas individuais de manifestações artísticas, não raro, apresentam dificuldades de recepção em painéis históricos demasiado amplos. Não cabe a nós, aqui, analisar se esse é um fenômeno cultural brasileiro ou parte da história do próprio pensamento ocidental, mas precisamos reconhecer que artistas dotados de forte individualidade, como Person, possuem, a grosso modo, dificuldades em serem contemplados nas pesquisas das manifestações artísticas de uma época, a não ser que sejam subsumidos a um grupo.

Durante muito tempo, a produção cinematográfica de Person foi encarada como parte de um Cinema Novo urbano. O delineamento de um perfil mais complexo de Person, no entanto, permite verticalizar as suas peculiaridades frente aos movimentos culturais do período. $\mathrm{O}$ cineasta demonstra idiossincrasias que apenas muito arduamente se submetem a essa classificação. Neste artigo, veremos como essa imagem do artista e do cineasta, ao mesmo tempo cinematográfica e de afirmação identitária, permite relativizar algumas homogeneidades reinantes em seu tempo. ${ }^{2}$

Quando de sua estreia no cinema ${ }^{3}$, o país estava em plena redefinição política, devido ao golpe civil-militar de 1964 . O cinema brasileiro com foco em São Paulo engatinhava como iniciativa industrial, graças à persistência de pioneiros remanescentes dos estúdios da década anterior. Por outro lado, o sucesso em festivais internacionais e diante da crítica estrangeira garantia ao Cinema Novo e a seus cineastas, Glauber Rocha, Nelson Pereira dos Santos etc., uma exposição de repercussão mundial. ${ }^{4}$ Nesse cenário cultural e político, afinal, naquele contexto, mostrava-se impossível separar essas duas esferas, uma polarização se configurava, o que, com o passar dos anos, se consolidaria com tonalidades nitidamente teleológicas.

De acordo com as versões mais consolidadas desse télos dicotômico, os cinema-novistas seriam os fundadores de um cinema brasileiro de fato, enquanto os paulistas somente tentavam copiar, sem sucesso, os modelos estrangeiros de produção. O modelo "industrialista-universalista", também chamado simplesmente de "universalista" ou "cosmopolita", procuraria, assim, apenas "absorver, sem críticas, formas de produção e moldes artísticos estrangeiros". ${ }^{5}$ Essa paisagem dividida em dois horizontes não imiscíveis tornou-se bastante influente como fator de explicação e compreensão dos movimentos cinematográficos do período. É lícito defender, no entanto, as limitações dessa fórmula binária que se apresentava distante da complexidade do jogo de relações observáveis no período.

A produção e a trajetória de Person promovem uma dessas fissuras que não permitem que um tecido temporal demasiado límpido e cristalino venha a ser produzido. Já no período de sua produção, não faltaram tentativas de, através de classificações previamente existentes, inserir Person em um quadro polarizado. Sua singularidade, porém, funciona como um sintoma de uma rede de relações múltiplas que perturbam qualquer tentativa de homogeneização. ${ }^{6}$

\section{Person: apontamentos de uma trajetória}

Person se envolveu em suas primeiras experiências nas artes como ator em peças do Teatro Brasileiro da Comédia (TBC) e também como

${ }^{2}$ As disputas em torno de Person que aqui analisamos foram durante muito tempo esquecidas. O cineasta, até pouco tempo atrás, surgia nas pesquisas acadêmicas como pacificamente inserido no grupo cinema-novista. Como exemplo, ver, BIN, Marco Antonio. A São Paulo de Person: uma análise socioespacial do filme São Paulo S. A. Dissertação (Mestrado em Comunicação e Semiótica) - PUC-SP, São Paulo, 1998, NORITOMI, Roberto Tadeu. Uma alternativa urbana dentro do cinema novo. Dissertação (Mestrado em Ciências Sociais) - USP, São Paulo, 1997. A inclusão de Person nas fileiras do Cinema Novo pelos estudiosos de cinema, que por muito tempo foi tácita, tem sido desfeita nos últimos 15 anos de pesquisa, gerando um razoável consenso de que suas diferenças pessoais o excluem do movimento. Sobre isso, ver COSTA, Candida Monteiro Rodrigues da. Em busca de Luiz Sérgio Person: cineasta na contramão: 1960-1976. Dissertação (Mestrado em Comunicação Social) - PUC-Rio, Rio de Janeiro, 2006.

${ }^{3}$ Além de São Paulo S. A., sua estreia de fato, Person dirigira uma comédia na década de 1950 para uma pequena produtora. Por desentendimentos com os financiadores, o filme fora cancelado. Relançado nos anos 1960 como Um marido para três esposas, seria assinado por Renato Grecchi. Ver PERSON, Luiz Sérgio. Entrevista para o Luz, Câmera \& Ação. In: LABAKI, Amir (org.). Person por Person. São Paulo: A. Labaki, 2002, p. 30. Entrevista originalmente concedida para Joanna Fomm durante o programa da TV Cultura Luz, Câmera \& Ação, em 1975.

${ }^{4}$ Cf. FIGUEIRÔA, Alexandre. Cinema Novo: a onda do jovem cinema e sua recepção na França. Campinas: Papirus, 2004.

${ }^{5}$ RAMOS, José Mário Ortiz. Cinema, Estado e lutas culturais: anos 50, 60, 70. Rio de Janeiro: Paz e Terra, 1983, p. 23.

${ }^{6}$ Cf. AGAMBEN, Giorgio. Que c'osèun dispositivo? 3. ed. Roma: Nottetempoed, 2013. 
${ }^{7}$ Para uma visão geral sobre as demandas por reformas, ver GOMES, Angela de Castro e FERREIRA, Jorge. 1964: o golpe que derrubou um presidente, pôs fim ao regime democrático e instituiu a ditadura no Brasil. Rio de Janeiro: Civilização Brasileira, 2014.

${ }^{8}$ Ver ROCHA, Glauber. Uma estética da fome. Revista Civilização Brasileira. Rio de Janeiro, n. 3, jul. 1965. Ninho Morais questiona se Glauber Rocha já teria visto o filme quando redigiu o manifesto ou o teria inserido no texto apenas através de um resumo de Gustavo Dahl e Paulo César Saraceni, companheiros de Person desde a época do Centro Sperimentale, teriam feito a ele a respeito do filme. A dúvida é pertinente, uma vez que o filme foi finalizado em sua montagem somente em junho de 1965, para ser lançado comercialmente em outubro daquele ano, e a V Rassegna, onde Glauber apresentou sua revolucionária tese, ocorrida em janeiro do mesmo ano. Mas a dúvida se desfaz quando percebemos que a menção ao filme de Person está entre os acréscimos que o texto de Rocha recebeu para a publicação na Revista Civilização Brasileira, em julho, mas não na versão apresentada como tese em Gênova. Portanto, Rocha redigiu essa segunda versão após o filme estar montado e já premiado em Pesaro. Glauber provavelmente assistiu a um copião do filme, talvez exibido por Person para um público seleto. Ver MORAIS, Ninho. Radiografia de um filme: São Paulo S. A, de Luiz Sergio Person. São Paulo: Imprensa Oficial, 2010, p. 357 e ss. Para a discussão sobre as várias versões do manifesto de Glauber Rocha, ver SILVA, Jaison Castro. Autonomia e Cinema nacional: a V Rassegna e o Cinema Novo. Anais do VII Simpósio Nacional de História Cultural. São Paulo, Universidade São Paulo - USP, 2014. Disponível em <http:// gthistoriacultural.com.br/VIIsimposio/Anais/Jaison\%20Castro\%20Silva.pdf>.

${ }^{9}$ Ver NEVES, David E. Cinema Novo no Brasil. Petropólis: Vozes, 1966. diretor de teleteatro para emissoras locais. No início de 1960, o diretor foi para a Itália, onde estudou no Centro Sperimentali de Cinema. Quando retornou da Europa, ele encontrou um contexto bastante diferente de quando deixou o Brasil. Referências ao cinema cubano, agitação nos grupos sociais, demandas por reformas diversas, incluindo a agrária, tornavam-se pauta de vários setores sociais ${ }^{7}$ e também tomavam de assalto os meios culturais e cinematográficos.

O sucesso de São Paulo S. A., no entanto, viria a gerar intensas demandas para que ele definisse, de maneira mais incisiva, sua posição política. Glauber Rocha, em seu famoso manifesto "Uma estética da fome", produzido por ocasião da V Rassegnadel Cinema Latino-americano, em 1965, em Gênova, Itália, menciona diretamente essa obra de Person como parte do Cinema Novo, inserindo Luciana, a coprotagonista, na lista das personagens do movimento, de acordo com o texto do manifesto, marcado por mulheres fortes. ${ }^{8}$

No mesmo sentido, o recenseamento promovido por David Neves dos integrantes do movimento, gestado por vários anos e publicado em 1966, localiza o nome de Person junto aos 21 diretores do Cinema Novo. ${ }^{9}$ O cineasta paulista reconhecido pelos cinema-novistas como representante do movimento em São Paulo, assim como outros nomes como Maurice Capovilla.

Dispostos a ocupar estrategicamente territórios e na esteira do impacto de São Paulo S. A., os cinema-novistas buscaram atrair o estreante ao seu círculo, motivados tanto pela qualidade do filme quanto pela aparente afinação da posição política de Person com os demais componentes do grupo..$^{10}$ Havia uma estratégia mais ou menos declarada, por parte de alguns críticos e cinema-novistas, de inserção de toda a prática de cinema de qualidade daquele recorte nas fileiras do Cinema Novo. ${ }^{11}$ Isso ocorria, principalmente, no contexto internacional.

Em suas declarações, podemos observar que Person não somente reconhecia o papel crucial dos cinema-novistas, naquele momento do cinema brasileiro, mas salientava a importância pessoal dessa renovação sobre sua carreira:

Ao retornar da Europa, em fins de 1963, encontrei uma outra realidade cinematográfica no país. Meus anseios e possibilidades se integraram a essa nova fase em que um cinema verdadeiramente brasileiro deixava de ser uma soma de fatos ocasionais e começava a ganhar dimensão de conjunto. Embora já escrito na Itália, "São Paulo S.A." nasceu aí. É produto disso. Dificilmente tomaria, em outras circunstâncias, forma e vida assim como é. [...] Firmou-se uma autonomia fundada no cinema de autor, na afirmação pessoal do realizador cinematográfico [...]. ${ }^{12}$

A autoinserção de Person em um "cinema verdadeiramente brasileiro" parecia confirmar seu flerte com os cinema-novistas, da mesma forma como sua menção às forças repressoras da ditadura - "ameaças à livre criação" - deixava clara sua posição política. Ao mesmo tempo, a concepção de um campo cinematográfico autônomo, constatada em eventos como a V Rassegna ${ }^{13}$, equivaleria a uma constatação inevitável - tanto quanto a concentração em um "cinema de autor", em sua afirmação "pessoal" - de criação subjetiva a partir de um projeto intelectual e estético independente.

Ainda assim, como veremos, Luiz Sérgio Person evidencia uma posição que permite a sua inserção no Cinema Novo apenas com um des- 
prezo de determinadas peculiaridades de sua proposta de cinema. Mesmo em termos políticos, e não somente estéticos, a posição de Person e a dos cinema-novistas dificilmente podem ser completamente sobrepostas. Marta Nehring assegura que a singularidade Person o deixava em uma situação delicada em um quadro de blocos opostos. ${ }^{14}$

O contexto político-ideológico pré-1964 fazia Person questionar se aquele "clima político esquerdista" possuía algum fundamento sólido no qual se apoiar, revelando cautela ante o que ele chamaria de euforia da esquerda. ${ }^{15}$ Além disso, suas posições em relação à prática de cinema, como observaremos a seguir, também representavam uma postura singular. Diferenças bastante significativas que são imprescindíveis para compreendê-lo em sua especificidade, a partir das características internas de sua proposta de cinema.

\section{Disputas em torno do jovem cineasta: uma temporalidade bastante pessoal}

Ao analisarmos as críticas na época do lançamento de São Paulo S. A., em outubro de 1965, percebemos que a recepção estava longe de aclamar uma pacífica classificação sob a égide do Cinema Novo. Entre o engajamento, com a denúncia de certos aspectos sociais, e o formalismo, por sua narrativa acronológica e os recursos estéticos colhidos do cinema europeu moderno, com efeito, o novo filme desafiava a crítica a situar o cineasta frente a um quadro de estrita dualidade.

O flerte frontal de Person em relação aos cinema-novistas autorizava que Francisco Luiz de Almeida Salles visse o cineasta como integrante do grupo. Salles, crítico decano de O Estado de S. Paulo, foi um dos principais nomes da crítica cinematográfica paulista. Junto a Paulo Emílio Salles Gomes, ele demonstrou efusivo apoio ao Cinema Novo, assumindo a defesa de um "cinema verdadeiramente brasileiro", após a I Convenção da Crítica, realizada na Cinemateca Brasileira, em 1960. Coordenado por ambos, o evento reuniu críticos de vários estados brasileiros que defendiam teses geralmente conectadas à expressividade do nacional na nossa cinematografia. ${ }^{16}$ Nessas circunstâncias, Salles se preocupou em observar o parentesco na juventude do diretor paulista Luiz Sérgio Person e dos cinema-novistas:

Não era possível, tinham razão os jovens, nos limitarmos [os paulistas] a um cinema de deleite, de fruição meramente estética, de divertimento superficial e público. [...] [Os paulistas] insistiram no cinema inautêntico, de fabricação de dramazinhos alienados, à maneira deste ou daquele paradigma consagrado. [...] Agora Luiz Sérgio Person dá a contribuição última de São Paulo a esse surto fecundo do nosso cinema atual, com o seu São Paulo S.A. [...] A atitude que assume tem semelhança com a dos outros novos do cinema brasileiro, buscando o ponto de crise, a linha de conflito, de onde nasce o drama, e não a exaltação superficial ou o documento neutro. Fazendo cinema na cidade ou nos sertões do Nordeste, o que procura hoje o nosso cinema não é o pitoresco nem o exotismo, mas a verdade..$^{17}$

Nesse caso, Person servia, inclusive, como um alerta aos paulistas, sobrando farpas para o cinema técnico-industrial, fabricante de "dramazinhos alienados" e vinculados a uma cinefilia de inspiração internacional e cosmopolita. Para Salles, os paulistas precisavam acordar para um cinema
${ }^{10}$ Cf. DAHL, Gustavo, DIEGUES, Carlos, NEVES, David, SARACENI, Paulo César e VIANY, Alex. [Vitória do cinema novo]. In: AVELLAR, José Carlos. (org.). O processo do cinema novo. Rio de Janeiro: Aeroplano, 1999, p. 115. Originalmente publicado em Revista Civilização Brasileira, Rio de Janeiro, n. 3, 1965.

${ }^{11}$ Sobre isso, ver DAHL, Gustavo. [carta] mar. [?], 1963, Paris [para] ROCHA, Glauber. [s.n.]. Situação do mercado europeu para o filme brasileiro e festivais de cinema. In: BENTES, Ivana (org.) Glauber Rocha: cartas ao mundo. São Paulo: Companhia das Letras, 1997.

${ }^{12}$ PERSON, Luiz Sérgio. Person: autoanálise e cinema verdadeiro (depoimento concedido a Miriam Alencar - parte 1). Folha de S. Paulo, São Paulo, 17 abr. 1967.

${ }^{13}$ Ver SILVA, Jaison Castro, op. cit.

${ }^{14}$ Cf. NEHRING, Marta. São Paulo em movimento: a representação da cidade nos anos 1960. Tese (Doutorado em Ciências da Comunicação) - USP, São Paulo, 2007, p. 147 e ss. Tal oposição binária já era forte na efervescência daquele momento, como podemos constatar em vários documentos da época. Devido a limitações de espaço, aqui nos restringiremos a citar apenas dois exemplos, entre os muitos disponíveis, dessa dicotomia presente tanto na análise posterior como nos embates do período: GOMES, Paulo Emílio Salles. Rascunhos e exercícios. Suplemento Literário de O Estado de S. Paulo. São Paulo, 20 jun. 1958, p. 5, e FARIA, Octavio. Por um cinema-síntese. Filme Cultura, ano II, n. 8, Rio de Janeiro, mar. 1968. Para uma visão mais ampla do assunto, ver SILVA, Jaison Castro. A tessitura insuspeita: cosmopolitismo, cinema nacional e trajetórias do olhar em Walter Hugo Khouri e Luiz Sérgio Person (1960-1968). Tese (Doutorado em História) - UFC, Fortaleza, 2014. 
${ }^{15}$ Cf. PERSON, Luiz Sérgio. Depoimento. São Paulo, fev. 1967. Datilografado, sem publicação, encontrado nos arquivos da Cinemateca, p. 5. Ao futuro companheiro de roteiros, JeanClaude Bernardet, Person diria: "[Ele] achava que o pessoal do Cinema Novo, o Glauber entre outros, estavam cheios de ilusão e se comportavam como meninos, que não estavam percebendo a realidade política e que não ia ter revolução nenhuma.". BERNARDET, JeanClaude. In: COSTA, Candida Monteiro Rodrigues da, op . cit., p. 101 (trecho obtido a partir do roteiro decupado do copião do filme Person (2007), de Marina Person).

${ }^{16}$ Uma coletânea de suas críticas foi organizada por Ruy Castro: ver SALLES, Francisco Luiz de Almeida. Cinema e verdade: Marylin, Buñuel, etc. por um escritor de cinema. São Paulo: Companhia das Letras, 1988. Uma tese nacionalista, defendida na Convenção de Críticos e que, posteriormente, se converteu em texto seminal para se entender o cinema no período está contida em GOMES, Paulo Emílio Salles. Uma situação colonial? In: Crítica de Cinema no Suplemento literário (vol. 2). Rio de Janeiro: Paz e Terra, 1981.

17 SALLES, Francisco Luiz de Almeida. Em louvor de Person. Suplemento Literário de O Estado de S. Paulo, São Paulo, 9 out. 1965, p. 5.

${ }^{18}$ SGANZERLA, Rogério. Encontros. São Paulo: Azougue, 2007.

${ }^{19}$ Idem, Filmar São Paulo. Suplemento Literário de O Estado de S. Paulo, São Paulo, 23 out. 1965, p. 5.

${ }^{20}$ Sganzerla se aproximava dos referenciais da fenomenologia no cinema, uma das tendências da crítica cinematográfica de então. Ver idem, A 'câmera' cínica. Suplemento Literário de O Estado de S. Paulo, São Paulo, 11 jul. 1964, p. 5, e GRÜNEWALD, José Lino. Um filme é um filme. São Paulo: Companhia das Letras, 2001.

21 Referência ao teórico de cinema Jean Epstein, outro elemento do código disponível da época com o qual as críticas de Sganzerla efetuam um diálogo. Sobre isso, ver ainda RITTNER, Maurício. Atualidade de Epstein. Filme Cultura, ano I, n. 4, Rio de Janeiro, mar.-abr. 1967. emancipado da mera "fruição estética", o que resultaria em um "cinema inautêntico".

No seu "louvor a Person", como Salles intitulou a sua crítica, ele aproveitou para apoiar a iniciativa urbana do Cinema Novo - uma das principais bandeiras que os cinema-novistas assumiram em sua segunda fase -, uma vez que, pautada pelo mesmo cinema em busca da "verdade", adquiria a versatilidade necessária para construir narrativas localizadas tanto no campo quanto na cidade, no Nordeste quanto na metrópole, inserindo São Paulo S. A. nesse cenário.

Rogério Sganzerla, na época crítico do Suplemento Literário de $O$ Estado de S. Paulo, apontou, por seu turno, severas contradições entre a proposta de Person e a dos cinema-novistas. Sganzerla se tornou o principal representante do cinema marginal, a partir de $O$ bandido da luz vermelha (1968), filme que dirigiu. Nos anos seguintes, ele se notabilizou como ferrenho opositor dos cinema-novistas, denunciando-os como traidores de um projeto de cinema independente. ${ }^{18}$ Em seu ensaio sobre o cineasta paulista, Sganzerla não poupou elogios à iniciativa de Person, em filmar a metrópole, ressaltando que a cidade de São Paulo dificilmente se dobra ao "registro fílmico":

Luiz Sérgio Person renunciou aos 'décor' excessivamente parciais e por isto filmou S. Paulo como nunca até então [...] filmando tudo. [...] Nossa maior fotogenia sempre esteve aí, diante de todos: no ritmo diário das avenidas, no tráfego congestionado, nas galerias e bares. [...] Person percebeu a situação. Por isso insistiu nas filmagens diretas, em exteriores reais. Soube levar a câmera às ruas, fazê-la andar com estilo. [...]. [Em Person] ao contrário de Glauber Rocha, [...] o problema social [é abordado] em termos individuais [...]. Na tela, o homem não é causa, não simboliza ideias ou proposições coletivas - é um efeito; sofre na carne os conflitos ditados por nossa civilização [...]. Daí o realismo interno de uma obra que trata de maneira honesta e atual o tão batido tema da angústia individual projetado no coletivo. [...] [Fazendo uso de] avanços e rupturas resnainianos, suas obsessões fellinianas, com seu cansaço antonionico e, finalmente, na inquietação personiana [...] não hesita em usar recursos modernos. Desmistifica a cinematografia vigente, destrói o complexo de seriedade, ameaça toda a organização atual. ${ }^{19}$

De acordo com o olhar do analista, Person soube captar a cidade em uma busca de "totalidade", "filmando tudo", não evitando as dificuldades do cinema direto, em meio à multidão e, por fim, submeteu a metrópole, $\mathrm{o}$ corpo de imagens aparentemente indomável, ao registro. Uma experiência de corte, portanto, frente a uma massa de dados sensórios. ${ }^{20}$ Mas, para que a lâmina fosse afiada o suficiente para empreender a tarefa, fez-se preciso dominar um saber cinematográfico específico, emprestar "estilo" à câmera que anda pelas ruas. O que Person conseguiu em seu filme, nas palavras de Sganzerla, não se configura em mera documentação para registrar as cenas cotidianas de São Paulo. Daí que, mesmo premido pela urgência do registro da metrópole, sua câmera satisfez às necessidades de captar a "fotogenia" da cidade. ${ }^{21}$

No quesito humanismo, surgia, porém, no olhar de Sganzerla, a maior especificidade do filme de Person; o "homem" representado na tela não aparece como a causa, o motor dos processos, mas apenas como efeito de forças que não domina. Os personagens sofrem na "carne", em seus próprios corpos, os problemas morais da civilização. Sganzerla construiu um 
modo de ver para a imagem personiana em que os problemas humanos são visualizados em uma perspectiva de observação da realidade que ele denominacomo "realismo interno", uma opção de abordagem que insere os problemas no corpo dos personagens.

Além do mais, nas últimas palavras do trecho por nós destacado, Sganzerla brincava com o desfile dos onomásticos (Fellini, Antonioni etc.), não esquecendo o próprio Luiz Sérgio Person - "personiano" -, alçando-o à figura de "autor" e aproveitando também para lançá-lo à categoria daqueles que, ao abraçar o cosmopolitismo inerente à prática cinematográfica, não temem usar os recursos disponíveis do cinema moderno.

A partir dessa admissão do jogo das relações e trocas estéticas, da brincadeira formal, Person se revestiu do poder subversivo de "desmistificar" o cinema da época, contagiado por um "complexo de seriedade". O cineasta paulista atuou, portanto, como um desestabilizador de homogeneidades e surgiu para flexibilizar ossificações em marcha através de um cinema que admite, ainda que ironicamente, o jogo das intercambialidades das formas internacionais. ${ }^{22}$

Se, para Almeida Salles, as semelhanças entre o jovem Person e os jovens cinema-novistas pareciam inquestionáveis, Sganzerla, por sua vez, diagnosticava que o filme colidia com as coordenadas da dicotomia existente entre a temporalidade cinema-novista ou independente e a temporalidade técnico-industrial. Como podemos ver, a definição das imagens personianas estava atravessada pelas disputas, tentativas de captura e de corte.

\section{Person e o Instituto Nacional de Cinema}

O Instituto Nacional de Cinema (INC) foi criado, junto com a revista Filme Cultura, por um decreto-lei do presidente militar Humberto Castello Branco, que atendia a uma demanda de longa data da classe cinematográfica $^{23}$, o que não deixou de gerar polêmicas nesse segmento. ${ }^{24} \mathrm{~A}$ proposta do Instituto claramente era consolidar uma indústria cinematográfica que, freando os impulsos autorais menos comerciais, pudesse construir um cinema simultaneamente subjetivo e industrial..$^{25}$

Ely Azeredo, editor da Filme Cultura, periódico do INC, já havia se referido a Person como "sem respostas precisas, banhado de dúvidas, extrovertendo contradições" ${ }^{26}$ Azeredo, apesar de ser apontado como aquele que batizou o Cinema Novo, assumiu a posição de um dos maiores opositores do movimento, ainda que desfiasse, vez por outra, críticas positivas a alguns filmes do grupo, como Vidas secas (1963). Junto a Antônio Moniz Vianna, encontrava-se, geralmente, identificado a uma crítica de cinema voltada para um cinema universal, sem marcas de origem claras, portanto em direta oposição a qualquer cinema nacionalista. Com base nisso, escreveu a seguinte provocação a Person:

Só as próximas realizações de Luiz Sérgio Person, por exemplo, dirão se este realizador paulista, que se iniciou com São Paulo Sociedade Anônima (filme no qual alienação social e alienação existencial se interpenetram em um personagem concebido e interpretado lucidamente) é um artista comprometido com formas ideológicas e estéticas ou se, não resistindo à gravitação dominante no cinema mais empenhado [socialmente], aderirá às coordenadas do Cinema Novo. ${ }^{27}$

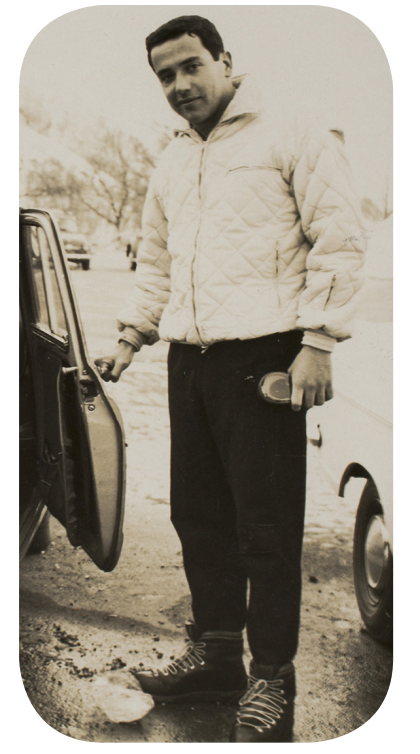

${ }^{22} \mathrm{O}$ crítico Arley Pereira, por exemplo, defendeu Person como "universal", opondo diretamente nacionalistas e universalistas: "Tentarão inverter os fatos ao seu gosto e apontar em 'São Paulo S. A.', o surgimento de uma temática tipicamente paulista, o que na verdade, se fosse o caso, não passaria de provincianismo". PEREIRA, Arley. São Paulo S.

A. Diário de Notícias, São Paulo, 7 out. 1965.

${ }^{23}$ Cf. SIMIS, Anita. Estado e cinema no Brasil. 2. ed. São Paulo: Annablume/Fapesp/Itaú Cultural, 2008.

${ }^{24}$ No cinema brasileiro a divisão leva à discussão. Folha de $S$. Paulo, São Paulo, 17 out. 1966. A matéria, uma entre muitas dedicada à polêmica, apresenta uma enquete com depoimentos de quatro cineastas contrários ao projeto (Glauber Rocha, Luís Carlos Rocha, Roberto Farias e Rui Santos) e quatro a favor (Walter Hugo Khouri, Luiz Sérgio Person, Gustavo Dahl e Joaquim Pedro de Andrade) da fundação do INC por decreto presidencial.

${ }^{25}$ Azeredo propunha um cinema "intelectual-industrial". Ver AZEREDO, Ely. Biáfora, a coragem de ser. Filme Cultura, ano I, n. 7, Rio de Janeiro, out.nov. 1967, p. 18.

${ }^{26}$ Idem, O novo cinema brasileiro. Filme Cultura, ano I, n. 1, Rio de Janeiro, jan.-jun.(?) 1966, p. 11.

${ }^{27}$ Idem, apud A crítica e o cinema novo II). Filme Cultura, ano I, n. 5, Rio de Janeiro, jul.-ago. 1967, p. 21. 
${ }^{28}$ PAIVA, Salvyano Cavalcanti (verbete). In: RAMOS, Fernão Pessoa e MIRANDA, Luís Felipe. Enciclopédia do cinema brasileiro. São Paulo: Senac, 2000, p. 413.

${ }^{29}$ Idem, apud A crítica e o cinema novo I. Filme Cultura, ano I, n. 2, Rio de Janeiro, nov.-dez. 1966, p. 27.

${ }^{30}$ PERSON, Luiz Sérgio, apud Cinema paulista espera a sua vez. Jornal da Tarde, São Paulo, 5 fev. 1966

${ }^{31}$ De acordo com o cinemanovista Gustavo Dahl, "[Na Vera Cruz] a noção de processo econômico cinematográfico terminava na produção [...] O Cinema Novo repetiu esses ciclos de produção [...]. Praticamente todos os estímulos governamentais do cinema se referem à produção". DAHL, Gustavo apud BERNARDET, Jean-Claude. Historiografia clássica do cinema brasileiro: metodologia e pedagogia. São Paulo: Annablume, 1996, p. 26
Podemos identificar no tom elogioso de Azeredo a Person, nesse trecho, como uma tentativa de pressionar Person a se definir e, ao mesmo tempo, lamentar sua inclinação esquerdizante. Em enquete publicada na Filme Cultura, Salvyano Cavalcanti de Paiva, crítico norte-rio-grandense, marcado pela "condenação veemente da produção cinema-novista" 28 , já se perguntava, mencionando a possível inserção de São Paulo S. A. entre os exemplares daquele movimento: "resta ver até onde irá Luiz Sérgio Person ". ${ }^{29}$

Um depoimento de Person, colhido no mesmo período, ajuda a responder a essa questão:

O fantasma dos estúdios falidos ainda pesa sobre nós [...] Persiste ainda o clima de desencanto provocado pelo fracasso da Vera Cruz e outros. No entanto, a maioria dos filmes produzidos naquela época não foram deficitários. O mal é que tiveram que arcar com o ônus da industrialização, pagar as instalações dos estúdios e a organização gigantesca que ficava por trás da produção de cada filme. [...] $\mathrm{O}$ ambiente de produção, de qualquer forma, foi dominado por um ceticismo total e a opinião generalizou-se no sentido de que o cinema era mau negócio. No entanto, a produção do filme é como qualquer outro investimento. O segredo desse negócio é a comercialização, nas duas fases posteriores à produção, isto é, a distribuição e a exibição [...] A má impressão que os homens de negócio têm da produção de filmes vem provar apenas que estão desatualizados e nada sabem a respeito dos problemas do cinema brasileiro. Precisamos fornecer-lhes dados. ${ }^{30}$

Percebemos, portanto, que Person não acreditava na tese do fracasso total da indústria de cinema paulista em função dos acontecimentos da década anterior. Ele identificava fatores de infraestrutura - e não formais e/ou conteudísticos - como os principais responsáveis pelo "ônus" que aqueles filmes, a maioria "não [...] deficitários", tiveram que pagar. $\mathrm{O}$ "fantasma", herdado devido a essa falência, porém, assombrava o cinema industrial paulista. Esse seria, portanto, o inimigo a ser combatido: o fantasma precisava ser exorcizado, o que não implicava necessariamente que a forma de produção ou a qualidade dos filmes devesse ser significativamente transformada.

Afinal, "a produção do filme é [um negócio] como qualquer outro investimento". Como podemos ver, o cineasta não se mostrou embaraçado ao assumir uma visão pragmática da produção de cinema e sustentar que a lucratividade deveria vir justamente no investimento de setores desprezados na produção de um filme no Brasil, ou seja, a distribuição e a exibição. ${ }^{31}$ Se os homens de negócio tivessem os "dados" corretos sobre o cinema nacional e demonstrassem tino empreendedor suficiente para se atualizar sobre o novo momento da indústria, o investimento na produção cinematográfica paulista seria possível uma vez mais.

Desse modo, para Person, os filmes seriam obras de arte, vindos de um autor, centrados na realização pessoal, mas nada disso impedia que eles se tornassem dados em uma planilha à disposição dos investidores. A partir dessa perspectiva, podemos mesmo supor que o ideal de cinema "intelectual-industrial" do INC não estava tão distante dessas reflexões de Person.

Nas páginas de Filme Cultura, dali a alguns meses, Person apresentou mais indícios de seu posicionamento. Ele afirmou o seu não alinhamento nem à temporalidade técnico-industrial, à moda paulista, nem à temporalidade do cinema independente, ao estilo carioca. Em uma entrevista 
chamada "Person e o cinema paulista", cujo título praticamente funciona como um convite à autodefinição, o entrevistador Alfredo Sternheim, futuro cineasta, ligado à produção cinematográfica de São Paulo, indagou logo na primeira pergunta: "Como se coloca no panorama cinematográfico brasileiro?"

[Person] Eu e todos os realizadores paulistas nos encontramos de uma forma ou de outra, isolados. Marcamos, assim, uma característica do cinema em São Paulo: cada um tem o cinema desvinculado do outro. [...] Não há - eu não diria unidade - mas uma certa equivalência de ideias, aspirações, alguma coisa que pudesse ser o elemento comum de definição do cinema paulista. Todos eles [os cineastas] o são na medida que se encontram marginalizados e através dessas individualidades diversas de objetivos contrários, formam o todo [...].

[Entrevistador] Você se considera integrado no "cinema novo"?

[Person] Eu poderia dizer, num tom meio sério, meio brincadeira, que eu vejo como um caso engraçado sem muito sentido, a necessidade de enquadramento. Não posso dizer que faço parte de um grupo. Essa é a verdade. Há pessoas que necessitam de uma religião, de uma ideia gregária para sobreviver. O próprio cinema que faço, o meio em que vivo, de certa forma, contraria a idéia de me considerar "cinema novo" ou "velho". De fato, concordo, meu primeiro filme foi encampado pelo "cinema novo". Mas - aí eu discordo [...]. [Apesar disso] sem o "cinema novo", sem essa ideia inicial de "cinema novo", dificilmente colocaríamos em discussão ampla no Brasil o problema do cinema, quebrando a dissociação cultural que havia. ${ }^{32}$

Person apontou aspectos de sua formação como cineasta e sua origem social e artística como justificativas para não pertencer a nenhum movimento, nem ao Cinema Novo, nem ao "velho" cinema, como alguns definiam a temporalidade técnico-industrial. Em que pesem as ambivalências, Person endossou sua posição de isolamento, qualificando assim a sua prática cinematográfica e expandindo-a para todos os paulistas. $\mathrm{O}$ seu cinema seria uma ilha. Em meio ao cinema insular que, segundo ele, era praticada pelos paulistas, o cineasta, no entanto, acreditava em uma "certa equivalência", embora sem saber especificar melhor.

Podemos notar, seja como for, que Person ainda não enfatizava, frontalmente, a ruptura com o Cinema Novo. A despeito da autodefinição estimulada pelo entrevistador, Person mantinha o tom ambíguo, que se revelava, em geral, no vocabulário que usava, próximo aos que criticam o cinema não engajado, e nas reticências com que reforçava a importância do Cinema Novo para a valorização do cinema brasileiro e do cineasta-autor.

Essas hesitações em se apartar completamente do movimento eram compreensíveis desde que entendidas de acordo com uma observação cuidadosa do contexto daquela época. Em um período em que se definir politicamente surgia como elemento central e eram poucas as posturas claramente disponíveis para filiação, optar por uma posição exclusivamente individualista parecia algo bastante difícil..$^{33}$

Diante da radicalização de uma política de separação proposta, em diferentes momentos, por Sganzerla, Sternheim e o INC, Person ainda hesitava. Naquela circunstância, romper expressamente com o Cinema Novo e corroborar uma política de corte não se afigurava como uma opção estrategicamente segura. Deixar-se capturar pelos acenos provenientes de Glauber Rocha, Gustavo Dahl, Paulo César Saraceni e Almeida Salles mostrava-se mais sedutor.
${ }^{32}$ PERSON, Luiz Sérgio. Person e o cinema paulista (entrevista a Alfredo Sternheim). Filme Cultura, ano I, n. 5, Rio de Janeiro, jul.-ago. 1967, p. 21.

${ }^{33}$ Cf. NEHRING, Marta, op. cit., p. 153. 
${ }^{34}$ Cf. BERNARDET, Jean-Claude. Caso Naves. In: BERNARDET, Jean-Claude e Luís Sérgio Person. O caso dos irmãos Naves: chifre em cabeça de cavalo. São Paulo: Imprensa Oficial do Estado, 2004, p. 8 e 9 (roteiro do filme republicado com comentário de Jean-Claude Bernardet)

${ }^{35}$ Ver PERSON inicia nova película. O Estado de S. Paulo, São Paulo, 30 out. 1966, p. 11

${ }^{36}$ Idem, Depoimento, op. cit.

37 Recordemos que, em 1967, como resultado das políticas do INC, o número de filmes subira de 28, em 1966, para 44, cf. JOHNSON, Randal. The film industry in Brazil: culture and State. Pittsburgh: Pittsburgh University Press, 1987. Naves, de todo modo, era o primeiro grande lançamento do cinema paulista daquele ano. Por isso se explica, em parte, a atenção concedida pelo INC ao filme. Ver BIÁFORA, Rubem. O erro judiciário em $\mathrm{O}$ caso dos irmãos Naves, O Estado de S. Paulo, São Paulo, 4 jun. 1967, bem como SILVA, Jaison Castro. O cinema brasileiro diante de um presente incendiário: o filme $\mathrm{O}$ caso dos irmãos Naves (1967), de Luiz Sérgio Person, e o despertar das consciências durante o regime de exceção. Revista de Estudos Ibero-americanos, v. 43, n. 1 Porto Alegre, jan-abr. 2017. Disponível em <http:// dx.doi.org/10.15448/1980864X.2017.1.24762>

38 Ver Filme Cultura. Rio de Janeiro, n. 5, jul.-ago. 1967, p. 16 e 17.

${ }^{39}$ As opiniões de Viany e Gomes estão na coluna de Ely Azeredo no Jornal do Brasil. AZEREDO, Ely. O filme em questão: $\mathrm{O}$ caso dos irmãos Naves. Jornal do Brasil. Rio de Janeiro, 23 set. 1967. Em carta a Glauber, Bernardet reclamaria que os críticos julgavam que o filme era "sádico". Ver BERNARDET, Jean-Claude. [carta] São Paulo, 21 jul. 1967, [para] ROCHA, Glauber. Sobre Person e A hora dos ruminantes. In: BENTES, Ivana (org.), op. cit., p. 284

\section{O caso dos irmãos Naves: o centro de atenções do cinema paulista}

Em 1967, Person lançou seu filme seguinte, O caso dos irmãos Naves. Diferentemente do seu longa-metragem anterior, aí era notória preocupação com um despojamento em termos de estilo. Além disso, o cineasta apresentava um tema muito mais facilmente classificável como social, ao se debruçar sobre um erro judiciário que ocorreu durante o Estado Novo, que destruiu a vida de dois comerciantes na cidade de Araguari, Minas Gerais. Os irmãos do título foram presos e torturados pela polícia varguista por um crime que não cometeram (que nem sequer existiu), gerando uma narrativa claustrofóbica e cruas cenas de tortura.

Conforme o corroteirista Jean-Claude Bernardet ${ }^{34}$, o cineasta paulista acreditava que, naquele momento, o questionamento aos militares deveria ocorrer principalmente através de filmes que abordassem de maneira crítica o autoritarismo. Durante a produção, Person preocupou-se com a filmagem in loco, deslocando a equipe para Araguari, a cidade palco do episódio real, lidando com dezenas de atores não profissionais, apenas raramente fazendo uso de estúdios. Promoveu, ainda, oficinas de atuação, ministradas pelos atores profissionais do elenco, com a comunidade local. ${ }^{35}$

Person esforçava-se para imprimir à película o maior teor político possível, rebatendo de vez as acusações de formalismo que recebera por conta de São Paulo S. A. Ele demonstrara sua suscetibilidade às observações negativas em relação à sua estreia mais de uma vez. Naves seria nitidamente um filme-resposta. Em constantes declarações para explicar as suas opções, o cineasta insistia na ideia de que seu filme era antirromântico, documental, despojado e seco: “Um cinema até antiestético [...], um cinema antieterno [sic] - pois o tempo não está para as catedrais góticas - a um cinema voltado à realidade presente, destinado a servir à realidade presente $[\ldots]^{\prime \prime}{ }^{36}$

Person conseguiu articular uma megaestreia - obviamente, para os padrões da época -para Naves, inaugurando sua exibição em quatro salas ao mesmo tempo, o que era sintomático a respeito da posição do realizador naquele momento, alçado a uma espécie de cineasta-fenômeno da indústria cinematográfica paulista. ${ }^{37} \mathrm{~A}$ revista do INC ofereceu uma cobertura considerável à nova obra filme de Person, colocando-a na capa da sua edição número 5, de julho-agosto de 1967, com foto de Raul Cortez e Juca de Oliveira, os atores que interpretam os irmãos Naves e anunciando, também com destaque de capa, que o filme fora escolhido pelo Itamaraty para representar o Brasil no Festival de Cinema de Moscou. ${ }^{38}$

Apesar dos esforços de Person e Bernardet, $\mathrm{O}$ caso dos irmãos Naves contou com uma recepção problemática por parte de alguns setores da crítica. As opiniões negativas se prendiam em geral à crueza e à duração das cenas de tortura. $\mathrm{O}$ pioneiro historiador do cinema nacional, ex-cineasta e um dos maiores apoiadores do Cinema Novo desde a sua fundação, Alex Viany, embora elogiasse o filme, disse que elas fariam a alegria dos sádicos da plateia. O crítico mineiro Maurício Gomes Leite, um dos fundadores da Revista de Cinema (1954-1963), admirador declarado de Glauber Rocha e de Paulo Emílio Salles Gomes, de modo mais severo, considerou um equívoco o tratamento dispensado ao tema na película justamente devido a suas cenas de tortura demasiado longas. ${ }^{39}$

Nessa mesma linha de raciocínio se manifestou Armindo Blanco, crítico de cinema de $O$ Globo. $\mathrm{O}$ ensaísta português, recém-saído de $A$ Última Hora, periódico fechado pelo golpe militar de 1964, que seria o res- 
ponsável pela coluna de artes e cinema por mais de uma década naquele jornal, estabeleceu uma clivagem entre cinema paulista e Cinema Novo, aproveitando o filme de Person para reforçá-la. Ele reclamou da falta de matizes da abordagem e expandiu quase automaticamente sua crítica para o cinema de São Paulo:

\begin{abstract}
Aos roteiristas faltou senso de ironia para uma especulação sobre a doçura de nossos costumes [do Brasil]. Homens politizados, Persone Bernardet preferiram forrar-se na Carta da ONU, aliás um austero e nobre diploma de intenções. [...] Equívoco de Person? Sem dúvida, São Paulo tem tradições cinematográficas peculiares: a Vera Cruz, Biáfora, Lima Barreto. [...] Que tem São Paulo a ver com os irmãos Naves? [...]. [O resultado final foi] um cinema pesado como um bate-estaca e reverso da souplesse [sic] de São Paulo S. A. [...] leva a plateia à comunhão [sic] episódica da telenovela, pela esquematização enfática do contraste entre as dóceis ovelhas paisanas e o vilão que proclama [sua violência] diante do júri [...]. ${ }^{40}$
\end{abstract}

As observações de Blanco sobre o cinema paulista demonstram claramente o quanto o filme fora apropriado como alvo das rivalidades já existentes entre os diversos grupos de cinema. O crítico apontava que a abordagem dos direitos humanos em Naves não seria suficientemente adaptada à realidade local, porque destituída de fundamentação nos costumes da cultura brasileira. Além disso, o "esquema" maniqueísta dos personagens - dividido entre vítimas descamisadas rumo à desumanização e torturadores uniformizados com o monopólio da violência - teria o apelo sentimental de um melodrama, o que os transformava em figuras dignas de pena no intuito de cativar o espectador.

O filme de Person foi um dos campeões de bilheteria daquele ano. $\mathrm{O}$ INC registrou que $O$ caso dos irmãos Naves se tornou a quinta maior renda do cinema nacional em 1967..$^{41}$ Person somente tinha a lamentar, uma vez mais, a incompreensão por parte da crítica: "acho pouco compreendido até mesmo pelas pessoas que gostam dele"; e acrescentava que o público não especializado tinha aprovado o filme: "Refiro-me, especificamente, à gente de cinema". ${ }^{42}$

O sucesso alcançado pela aposta em um filme-denúncia configura uma daquelas situações em que os fios síncronos de uma homogeneidade parecem se fragilizar e estão em vias de se soltar. Contraditoriamente, Naves, que condenava o autoritarismo das ditaduras e a tortura desumana praticada pelos regimes que aboliam as garantias e liberdades individuais, tornava-se um dos principais vetores para que a proposta implantada pelo presidente militar Castelo Branco - o Instituto Nacional de Cinema e a Filme Cultura, que notoriamente abraçaram o filme - tivesse um de seus momentos de maior expressão.

\section{Uma equivalência: $o$ cinema paulista, afinal}

Com base no que foi exposto, que, apesar das divergências em torno de sua figura e prática, Person dificilmente pode ser encarado como cineasta independente à la Cinema Novo e que as "equivalências" e "aspirações" em comum no ambiente paulista, mencionadas pelo cineasta em Filme Cultura, são hoje mais fáceis de definir do que o eram no período da realização e da publicação da entrevista.

Os filmes e a carreira de Person despontaram em São Paulo a partir

\footnotetext{
${ }^{40}$ BLANCO, Armindo. Um dia as manchetes quando já era tarde. O Globo. Rio de Janeiro, 25 set. 1967.

${ }^{41}$ Ver Prêmios INC 1967. Filme Cultura. Rio de Janeiro, ano II, n. 9, 30 abr. 1968.

${ }^{42}$ PERSON, Luiz Sérgio, apud Cineastas em depoimento. Filme Cultura, n. 8, Rio de Janeiro, 6 mar. 1968 , p. 28.
} 
${ }^{43}$ Cf. MORAIS, Ninho, op. cit.

${ }^{44} \mathrm{Cf}$. XAVIER, Ismail. Alegorias do subdesenvolvimento: cinema novo, tropicalismo e cinema marginal. 2. ed. São Paulo: Cosac Naify, 2012. Ver também SHOHAT, Ella e STAM, Robert. Crítica da imagem eurocêntrica: multiculturalismo e representação. São Paulo: Cosac Naify, 2006.

${ }^{45}$ Cf. GALVÃO, Maria Rita. Origens do cinema independente em São Paulo. Texto de 1980, datilografado, encontrado nos arquivos da Cinemateca Brasileira. O cinema independente assumiu uma configuração própria no período. A independência do filme estava relacionada não somente a aspectos econômicos, como à autonomia em relação à indústria e/ou os modos tradicionais de produção, até porque o cinema brasileiro não possuía uma indústria consolidada, e a critérios ideológicos. $\mathrm{O}$ cineasta independente seria aquele que questionasse as formas de produção tradicionais no capitalismo, abrindo caminho para o híbrido "cinema independente-industrial". Person permite revisitar esse conceito, tornando-o, porém, ainda mais atravessado de contradições. Ver também BERNARDET, Jean-Claude e GALVÃO, Maria Rita. Cinema - repercussões em caixa de eco ideológica: nacional e popular na cultura brasileira. São Paulo: Embrafilme; Brasiliense, 1983.

${ }^{46} \mathrm{Cf}$. JOHNSON, Randal, op. cit.

${ }^{47}$ O terceiro, "Panca de valente" (1968), um western cômico, foi um fracasso de crítica e público, levando o cineasta a uma quase aposentadoria precoce do cinema. Nesse período (19681971), Person se dedicou quase exclusivamente à publicidade. Cassy Jones é o seu retorno como diretor, apostando uma vez mais na comédia. Ver PERSON, Luiz Sérgio, op. cit..

${ }^{48}$ Cf. JOHNSON, Randal, op. cit., p. 104-137. de outra tradição de produção industrial que, a duras penas, tentava se consolidar. Suas conexões com o teatro, como ocorria com boa parte dos cineastas paulistas, principalmente com o TBC (Teatro Brasileiro da Comédia), foram muitas. Seus filmes, ainda que realizados por produtoras independentes, mantiveram contratos de produção em firmes bases industriais, como era hábito em São Paulo.

Em São Paulo, S. A., os equipamentos de filmagem eram de Audrá Andrade, da Maristela, um dos estúdios cinematográficos da década de 1950, que surgiram na esteira da Vera Cruz. Seu método de trabalho baseava-se na lógica e rotina de produção industrial, inclusive na decupagem prévia das cenas a serem filmadas. Seu modus operandi, portanto, estava mais próximo da maneira industrial paulista, em que ele se inseriu desde o início da carreira e galgou passos de ascensão, o que, como se dizia então, era a lógica da Vera Cruz e das outras companhias. ${ }^{43}$

Com $O$ caso dos irmãos Naves - filme-resposta, marcado pela verticalização de uma singularidade, gravado sem o uso de estúdios e fazendo uso de atores amadores - ele foi visto, de modo quase paradoxal, como representante máximo do cinema paulista, sendo encampado pelo INC e por seus meios de divulgação. Dessa forma, o filme de Person tornou-se veículo para que a proposta industrial, capitaneada pelo INC e pela Filme Cultura, assumisse o papel de protagonista, convertendo-se, mesmo que temporariamente, em um instrumento capaz de galvanizar atenções para aquela prática de cinema.

Poderíamos prosseguir na enumeração das diferenças entre ambas as produções, algo que não passaria de um exercício inócuo se isso não servisse para revelar a especificidade do próprio Person. Para além da definição pela negação - o despojamento dos cinema-novistas do excesso técnico ${ }^{44} \mathrm{e}$ das premissas da industrialização capitalista não combinam com o esquema de produção de São Paulo S. A. e, mesmo, de $O$ caso dos irmãos Naves -, Person sustentou uma difícil posição particular em uma época de polarização política e conectou-se ao quadro da cultura cinematográfica paulista, que, de resto, estava distante de qualquer homogeneidade.

$\mathrm{O}$ seu cinema era independente e ainda assim industrial. ${ }^{45}$ Person seria, ao mesmo tempo, crítico de um sistema de produção e, de uma maneira complexa, imerso em uma teia de relações irremediavelmente constituintes de uma indústria de cinema, precária e descentralizada, como continuaria, por muitos anos, a ser a brasileira ${ }^{46}$ - não apenas a paulista. Sua posição somente seria melhor explicada, anos depois, em entrevista a O Pasquim. Com ela, podemos finalmente nos aproximar de uma imagem mais múltipla de Person, muitas vezes prenhe de contradições.

\section{"Sou um sujeito de uma formação anti-Cinema Novo": a entrevista a $O$ Pasquim}

Em 1972, Luiz Sérgio Person lançou o seu quarto longa-metragem, Cassy Jones - o magnífico sedutor, uma comédia leve. ${ }^{47} \mathrm{O}$ momento histórico era outro, e aqui não dispomos, infelizmente, de mais espaço para explorar mais aprofundadamente o seu contexto. Mas o INC, em parceria com a distribuidora Embrafilme, conseguira erguer uma estrutura, apesar das muitas dificuldades, para a produção e distribuição do cinema brasileiro, uma política consolidada por sucessos de bilheteria do Cinema Novo como Macunaíma (1969) e O dragão da maldade contra o santo guerreiro (1969).$^{48}$ Esses 
filmes haviam alçado os cinema-novistas a uma nova fase, embora o fim do movimento empurrasse cada vez o grupo para o que Carlos Diegues chamaria, algum tempo depois, de "monumentalização". ${ }^{49}$

Foi sob esse clima que veio a público a Person comédia de costumes de costumes de Person, que, em seguida, recebeu o convite para uma entrevista a $O$ Pasquim, periódico que misturava charges e política em quantidades explosivas e que revolucionou o meio jornalístico ao abordar questões que até então eram tabu no jornalismo impresso. Suas entrevistas eram famosas por admitir palavrões (ainda que sinalizados por asteriscos) e um copy desk menos rigoroso, que deixava fluir uma linguagem mais próxima daquela utilizada no cotidiano.

Os jornalistas Zélio, Geraldo Mayrink, Fernando Pessoa e Ruy Barbosa foram os responsáveis por entrevistar Luiz Sérgio Person. Mais descontraído e menos propositivo, o depoimento de Person mostrou-se bastante diferente daqueles concedidos a Alfredo Sternheim, na Filme Cultura, ou a Miriam Alencar, na Folha de S. Paulo, alguns anos antes. ${ }^{50}$ Tanto que o caráter fragmentário de seu pensamento, próprio de um fluxo espontâneo de raciocínio, sem preocupações formais, levou algumas pessoas a suspeitar que a conversa tenha se dado sob efeito de álcool. Logo no primeiro momento, Person assumiu uma posição defensiva. Provavelmente habituado à leitura de $O$ Pasquim, portanto ciente de que os entrevistadores em geral alfinetavam os entrevistados, ele decidiu ser o primeiro a partir para a provocação:

O mundo está contra mim. Depois estão vocês [os entrevistadores] [...]. Arte, no sentido geral, já nem tá existindo mais. Cinema é um negócio muito limitado, limitadíssimo! Dentro desse campo que me foi ensinado a viver, [contudo] eu acho que algumas coisas a gente pode fazer. [...] Em primeiro lugar, "São Paulo S. A." não é uma obra do Cinema Novo; segundo, não é contra o Cinema Novo; terceiro, é uma obra que precede o Cinema Novo. [...] Eu nunca fui sectário a não ser quando isso foi necessário, quando isso foi importante para conseguir alguma coisa. [...] Eu não sou sectário nem nada a não ser quando isso convém a uma ideia. [...] Sou um sujeito dessa cultura que nasceu com o teatro brasileiro, o bom teatro, o novo teatro brasileiro. [...] Eu fui do Cinema Novo quando interessou ao Cinema Novo. Eu não fui do Cinema novo quando não interessou ao grupo. Isso é muito importante. Aliás, graças a Deus, nunca pertenci a nenhum grupo de cinema no Brasil. [...] Eu estava formado por um grupo de pessoas que, não podendo fazer cinema, pelo menos tinham uma consciência estética que eu acho muito importante. Eu aprendi [isso] com Ruggero Jacobbi que [...] é um dos homens que mais influenciaram a estética no Brasil. [...] Sou um sujeito de uma formação anti-Cinema Novo, até pelas ideias. ${ }^{51}$

Um dos motivos da importância da entrevista, independentemente das polêmicas que ela provocou, está em uma reavaliação que Person realizou de seu próprio passado e, sobretudo, a respeito da cultura paulista da década de 1950. Tal foi o caso da explicação para algumas de suas posturas, principalmente nos anos iniciais de seu sucesso, logo após a estreia de São Paulo S. A. Person, por exemplo, assegurou que a sua participação a posteriori no Cinema Novo, por um curto período, teria sido apenas estratégica. Em sua fala, o pensamento de grupo surge como uma circunstância aceita, não sem certa violência que uma vez perpetrou contra si mesmo, ao se encaixar numa classificação prévia a fim de viabilizar a concretização de seus planos de cineasta. Segundo Person, ele somente teria sido "sectário" quando isso

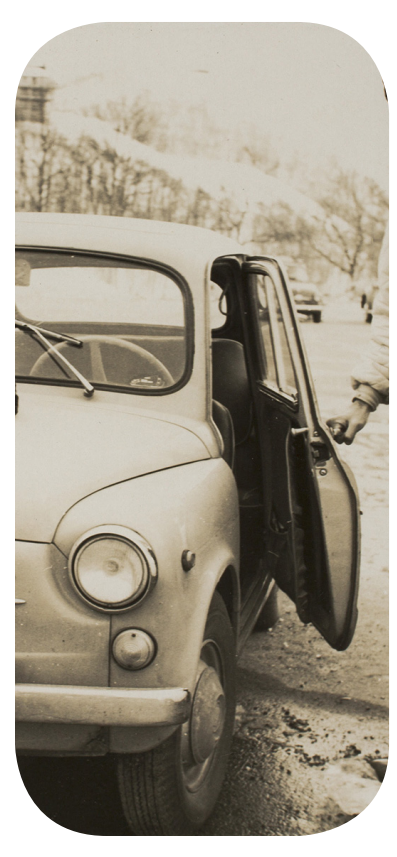

${ }^{49}$ DIEGUES, Carlos. Cacá Diegues: por um cinema popular, sem ideologias (entrevista concedida a PolaVartuck). $O$ Estado de S. Paulo, São Paulo, 10 set. 1978, p. 27. O cinemanovista Diegues fazia duras críticas à celebração em torno desse movimento cinematográfico, naquele momento já encerrado. Além da sua crítica à "monumentalização" do Cinema Novo, sua declaração mais memorável dizia respeito ao que era designado de "patrulhamento ideológico". Ao se transformar em memória, o Cinema Novo adquiriria um status que ossificaria algumas de suas propostas. Sobre o fim do movimento em 1971, ver FIGUEIRÔA, Alexandre, op. cit.

${ }^{50}$ Ver, o posicionamento, em 1967, de PERSON, Luiz Sérgio, op. cit.

${ }^{51}$ Idem, Entrevista. O Pasquim, n. 205, Rio de Janeiro, 5 a 11 jun. 1973. Republicado em PERSON, Luiz Sérgio. Entrevista a O Pasquim. In: LABAKI, Amir. Person por Person, op. cit. 
${ }^{52}$ Ver COSTA, Candida Monteiro Rodrigues da, op. cit.

${ }^{53}$ Sobre questões dessa natureza, ver KOSELLECK, Reinhart. Futuro passado: contribuição à semântica dos tempos históricos. Rio de Janeiro: Contraponto/PUC-Rio, 2006.

${ }^{54}$ Ver RAULINO, Berenice. $R u$ ggero Jacobbi: presença italiana no teatro brasileiro. São Paulo: Perspectivas/Fapesp, 2002. De acordo com Douglas Correa Jr., Jacobi seria um defensor do cinema-indústria. Ver CORREA JR., Fausto Douglas. A cinemateca brasileira: das luzes aos anos de chumbo. São Paulo: Edunesp, 2010, p. 133.

${ }^{55}$ PERSON, Luiz Sérgio. Carta. O Pasquim, n. 206, Rio de Janeiro, 3 jul. 1973, p. 16.

${ }^{56}$ Idem, ibidem. contribuiu para a concretização de uma ideia, negando de forma peremptória, com uma ênfase totalmente ausente em suas entrevistas anteriores, haver pertencido ao Cinema Novo, sendo, até mesmo "anti-Cinema Novo".

Claramente, notamos o que já podia ser intuído a partir das suas declarações anteriores. Person encarava como vantajoso em médio prazo para a sua carreira uma negociação com o Cinema Novo, mas já não sentia mais necessidade de negar suas conexões mais íntimas com o modo de produção paulista. A radicalidade de sua enfática negação em jamais ter se integrado de fato ao grupo demonstrava que Person estava em um diferente momento de sua autonarração identitária.

Em outro ponto da entrevista, ele afirmou que era anterior ao Cinema Novo, ao frisar que São Paulo S. A. fora "uma obra que precede" o movimento carioca. A pesquisadora Candida Monteiro Rodrigues da Costa, em sua dissertação sobre Person, questiona tal assertiva, uma vez que o movimento surgiu em 1961 e ele somente estreou efetivamente no cinema em $1965 .{ }^{52}$ Acreditamos, porém, que o cineasta não falava em critérios temporais exclusivamente cronológicos. Para Person, sua temporalidade pode ser situada como anterior ao Cinema Novo porque sua formação - entrelaçamento de experiências e estabelecimento de expectativas - estava relacionada à cultura cinematográfica da São Paulo dos anos 1950, campo a que admitia, no fim das contas, se vincular de maneira indissociável. ${ }^{53}$

$\mathrm{Na}$ entrevista, apesar das diferenças de ênfase, alguns aspectos da identidade que construiu para si durante a década anterior permaneciam intactos em Person. Sua principal alteração de postura, porém, se deu em relação a seu passado paulista. A respeito desse cenário cultural, Person assegurou que os homens da cultura, "não podendo fazer cinema, pelo menos" estavam munidos de "uma consciência estética". Ele reconhecia, por exemplo, o papel de Ruggero Jacobbi em sua formação cultural. Este italiano radicado no Brasil ministrou um curso de interpretação para os palcos a Person, foi corroteirista de Caiçara (1950) e dirigiu outros filmes da Vera Cruz, como Esquina da ilusão (1953), sem falar de dezenas de peças. Sua intensa atividade artística fez dele figura de destaque no ambiente dramatúrgico paulista. ${ }^{54}$

A entrevista teve repercussão negativa. Muitos acusavam Person de estar bêbado, outros garantiam que suas boutades eram apenas isso e não tinham fundamento. Na edição seguinte de O Pasquim, Person respondeu às críticas em uma longa carta, da qual transcrevemos um pequeno trecho: "Não levei a sério a minha entrevista que vocês publicaram [...]. [Mas] fique a mim atribuído somente o que é meu. Não posso acrescentar mais besteiras às muitas que já me pertencem". Ele ainda negou que com a carta estivesse realizando um mea culpa: "Achei ótima a entrevista e não estou nessa de autojustificativas". Na sequência, desfiou muitas críticas ao Cinema Novo. ${ }^{55}$

Em meio a isso, ofereceu mais alguns detalhes sobre sua "evolução e formação" cultural, "adquirida [devido a] um longo aprendizado técnico sem preocupações de expressão ou 'autenticidade' brasileiras, pescando aprendizado de italianos como [Adolfo] Celi", outro cineasta italiano ligado à Vera Cruz, nutrindo-se de "uma formação cultural importada". E finalizou, de maneira irônica: "Mas, por favor, não me leve a sério. Gratuitamente seu, L. S. Person". ${ }^{56}$ 
Luís Sérgio Person construiu o seu caminho em um quadro cultural polarizado. Situado entre os técnicos/industriais e o cinema independente, a sua recusa, mesmo que temporária, em assumir uma opção presta a inestimável contribuição de evidenciar o desgaste dos binarismos utilizados para explicar o período. É inegável, porém, que, apesar de sua singularidade - perceber a sua independência de pensamento não constitui tarefa difícil - Person estava inserido em um contexto de relações do "cinema paulista".

Eleger esse polo de produção como fator unívoco de sua afirmação identitária seria, no entanto, desprezar aquilo que o personagem possui de mais representativo, o que inclui o nó temporal que a análise de sua posição permite constatar. Precisamos atentar para a multiplicidade presente nas trajetórias de um mesmo personagem histórico e não nos rendermos ao vício do que se poderia denominar "autotelismo". Person, em suas contradições e multiplicidade, é a evidência que carrega sua riqueza justamente por apontar para um conjunto mais amplo de individualidades que não necessariamente se enquadravam naquele esquema de polaridades estritas, de resto ineficaz para servir como instrumental analítico que contemple a variedade de opções existentes no período. Ao historiador, diante do desafio de transformar tempo privatizado em tempo público ${ }^{57}$, impõe-se admitir o valor dos elementos contingenciais como sintomas das sensibilidades de uma época.

Desse modo, por outro lado, o estudo das peculiaridades da proposta paulista de cinema - em sua alteridade e especificidade históricas, de acordo com sua própria proposta e temporalidade, mesmo que afeita a mitos da indústria e dos estúdios - mostra-se de extrema importância para entender o papel de trajetórias individuais como a de Person. A independência de pensamento e seu posicionamento crítico em relação à política e à sociedade de sua época não o impediram de estabelecer laços, ainda que múltiplos e complexos, com uma concepção de cinema como a do INC, de ambições industriais e que, indiscutivelmente, flertava com um modelo autoritário de governo.

Paradoxos como esses atravessariam, tanto em São Paulo como em outros lugares, os passos do cinema brasileiro nas duas décadas do regime de exceção. No caso de Person, alguns fios dessas relações entre indústria e proposta cinematográfica autoral se juntam para compor uma imagem que assoma ao longe, trêmula e oscilante, e se recusa a se ossificar. Uma imagem que, justamente por sua fulgurância, perturba as homogeneidades circundantes, fragiliza télos dicotômicos, impossibilitando classificações ossificadas e ambientes culturais livres de fissuras. ${ }^{58}$

A autonarração personiana funde polos aparentemente imiscíveis, faz com que eles convivam sem contornar a sua inevitável fricção, retirando das fagulhas desse conflito irresoluto uma de suas contribuições mais originais. Nesses caminhos tortuosos, liberdade política, individualismo e propostas culturais alternativas são expressões que apenas se revelam, em seu entrelaçamento inextrincável, na análise de singularidades, que, invariavelmente, estimulam um olhar mais penetrante e diversificado sobre esse contexto.

Person morreu em um acidente de automóvel em 1976. Dessa forma, a sua vida artística ímpar foi abruptamente interrompida. Como ele voltou-se para a carreira teatral a partir de 1972, Cassy Jones foi seu último

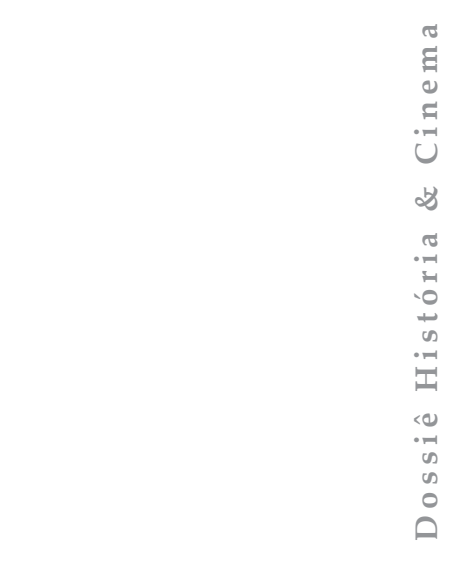

${ }^{57}$ Cf. RICOEUR, Paul. Tempo e narrativa. Campinas: Papirus, 1994, v. 1.

${ }^{58}$ Sobre isso, em outros contextos, ver DIDI-HUBERMAN, Georges, op. cit. 
longa-metragem. Seu gosto pela polêmica e incontornável disposição para exprimir sua individualidade, mesmo nas situações mais adversas, marcaram sua passagem por todas as artes em que atuou. Como procuramos demonstrar, sua contribuição cinematográfica, ainda que curta, acena com uma visão menos estática acerca do cinema brasileiro, convidando-nos a observá-lo com outros olhos, quiçá numa mirada menos dicotômica e redutora, aberta às múltiplas temporalidades que configuram o seu corpus de produções.

Artigo recebido em novembro de 2017. Aprovado em maio de 2018. 